\title{
Semi-active control using magnetorhelogical dampers with output feedback and distributed sensing
}

\author{
N.K. Chandiramani* and S.P. Purohit \\ Department of Civil Engineering, Indian Institute of Technology Bombay, Mumbai, India
}

Received 19 May 2011

Revised 2 January 2012

\begin{abstract}
Control of seismic response of a building fitted with magnetorheological dampers is considered using Optimal Static Output Feedback (OSOF) for desired damper forces. The Modified Bouc-Wen damper model is used and two control voltage laws based on the MR constraint filter, i.e., Semi-inverse Quadratic Voltage Law and Semi-inverse On-Off Voltage Law, are proposed. These appear to perform at least as well as an existing Clipped Voltage Law. Comparisons with available results from a robust reliability-based controller show OSOF control to be quite effective. Controlled response using OSOF is compared with Linear Quadratic Guassian (LQG) and passive-on controllers. Moderate to substantial reduction in maximum peak/RMS responses is mostly obtained with base configuration of sensors when using OSOF control, and controller CPU time reduces by two orders of magnitude. Parametric studies regarding sensor configuration and state/control weighting matrices are performed in order to obtain effective control. Effective OSOF control requires drift feedback with drift sensor preferably collocated with damper.
\end{abstract}

Keywords: Optimal control, output feedback, MR damper, Bouc-Wen model

\section{Introduction}

Semi-active devices (e.g. MR dampers) hold promise for vibration control since their properties can be adjusted in real time, and unlike active devices they do not inject energy into the system being controlled and have relatively low power requirements. The MR damper, using MR fluids that exhibit controllable yield characteristics, produces sizeable damping force for small input voltage.

The Bouc-Wen parametric model [1,2] describes the hysteritic behavior of MR dampers except near small velocities. This shortcoming was rectified by Spencer et al. [3] in their modified Bouc-Wen model, wherein additional damping and stiffness elements were used to model the low-velocity behavior and the accumulator, respectively, and voltage dependent parameters were introduced. Dominguez et al. [4] developed a current-frequency-amplitude dependent Bouc-Wen model and an identification method. Other damper models include the phase-transition model of Wang and Kamath [5], and modified LuGre friction model of Jiménez and Álvarez-Icaza [6] and Sakai et al. [7].

Various methods for controller design have been used with MR dampers. Due to the difficulty in inverting damper dynamics, predicting applied voltage that produces a desired damper force becomes a challenging task. Hence, various voltage laws have been proposed. Xu and Shen [8] used intelligent bi-state control with Bingham model and on-off current law for seismic response reduction. Dyke et al. [9] used acceleration feedback based Linear Quadratic Gaussian (LQG) control with modified Bouc-Wen model and a Clipped Voltage Law (CVL) based on desired and

\footnotetext{
* Corresponding author: N.K. Chandiramani, Professor, Department of Civil Engineering, Indian Institute of Technology Bombay, Powai, Mumbai 400076, India. Tel.: +91 22 25767311; Fax: +9122 25767302; E-mail: naresh@ civil.iitb.ac.in.
} 
measured damper forces. Desired damper force were obtained from measured accelerations, displacement, and damper force, thereby replacing the observer with a convolution integral. Jansen and Dyke [10] compared various control strategies using different voltage laws. Chang and Zhou [11] used LQR control with a recurrent neural network model for damper inverse dynamics. Response attenuation of connected buildings using LQR control was studied by Motra et al. [12] for clipped/neural-network based voltage laws. Yuen et al. [13] used reliability based robust linear controller design with a clipped voltage law. Prabhakar et al. [14] used $H_{\infty}$ control and genetic searching to enhance the performance of a semi-active system.

Most controller designs studied above are either based on full state feedback (requiring state measurement which is usually not feasible, or state estimation which forms a time intensive operation of the controller), or result in complex compensator structures. Optimal Static Output Feedback (OSOF) control avoids observer design, has a simple compensator structure, and produces the desired control force directly from a few measured outputs. Chung et al. [15] derived non-linear design equations for OSOF control and applied them to seismically excited systems. Matheu et al. [16] considered sliding mode control of a linear building system fitted with active tendon and active bracing, using output feedback for sliding surface design and Lyapunov's direct method for controller design. Purohit and Chandiramani [17] considered OSOF for a low order building system fitted with an MR damper and having fixed sensor configuration. Thus, application of OSOF in structural control are very few, and to the best of our knowledge unavailable for high order systems with multiple sensor configurations and MR dampers.

The aims and scope of the present paper are as follows: (i) To implement OSOF control for a seismically excited building system fitted with MR dampers, and assess its efficacy vis-a-vis other controllers such as Passive-on control (using constant damper-saturation voltage) and LQG control (using control voltage laws given below). OSOF control is also compared against available results from the robust reliability-based controller of Yuen et al. [13]. Peak and RMS responses are used for comparison amongst controllers. (ii) To derive voltage laws that yield better control. This is a non-trivial task when the dampers are modeled using the hysteritic modified Bouc-Wen element, as done herein. In that case the damper dynamics is not readily invertible, i.e., predicting the damper input voltage that produces a desired damper force is difficult. Hence, two control voltage laws, i.e., Semi-inverse Quadratic Voltage Law (SQVL) and Semi-inverse On-Off Voltage Law (SOOVL) based on the MR constraint filter, are proposed as an alternative to the existing Clipped Voltage Law (CVL). (iii) To assess the effect of sensor configuration and performance index on control. In this regard, the type of output fed back, placement/number of sensors, response quantity (i.e., displacement, interstorey drift, acceleration) being weighted in the PI via state weighting matrix $\mathbf{Q}$, and control weighting matrix $\mathbf{R}$ are varied in order to obtain effective control.

The paper is organized as follows. Section 1 contains a brief introduction, literature review, and aims and scope of the paper; Section 2 describes the structural and MR damper models; proposed voltage laws are derived in Section 3; Section 4 describes theory and implementation of OSOF control, and a modification when using acceleration feedback; Section 5 presents results and discussions, including comparisons with available results; and Section 6 contains the conclusions and future scope.

\section{System model}

A ten storey building, modeled as a plane frame with rigid slabs, with masses assumed lumped at storey levels, is considered with either a single damper placed at ground storey or two identical dampers placed at lower two stories. Figure 1 shows the structure with closed-loop feedback. The equation of motion is given by $\mathbf{M}_{s} \ddot{\mathbf{x}}+\mathbf{C}_{s} \dot{\mathbf{x}}+\mathbf{K}_{s} \mathbf{x}=$ $\mathbf{G f}-\mathbf{M}_{s} \mathbf{L} \ddot{x}_{g}$. Here $\mathbf{M}_{s}=\operatorname{diag}\left[m_{i}\right] ; \mathbf{C}_{s}=\alpha_{m} \mathbf{M}_{s}+\alpha_{k} \mathbf{K}_{s}$ (Rayleigh damping); $\mathbf{K}_{s}$ is tridiagonal with $K_{i i}=k_{i}+k_{i+1}, K_{i, i+1}=-k_{i+1}, K_{i, i-1}=-k_{i} ; \mathbf{L}=\left[\begin{array}{ll}1 & 1 \ldots 1\end{array}\right]^{T} ; \ddot{x}_{g}$ is the earthquake excitation (ground acceleration); $\mathbf{x}=\left[\begin{array}{ll}x_{1} & x_{2} \ldots \\ x_{10}\end{array}\right]^{T}$ is the displacement vector of the ten storeys measured relative to ground; $\mathbf{G}$ defines the location of MR dampers; $f$ is the applied control force vector as obtained from Eq. (3) for each damper. For the one-damper case $\mathbf{G}=\left[\begin{array}{lllll}-1 & 0 & 0 & \ldots & 0\end{array}\right]^{T}$ and $\mathbf{f}=f$. For the two-damper case $\mathbf{G}$ is a two-column matrix with $G_{i j}=0$ except $G_{11}=G_{22}=-G_{12}=-1$, and $\mathbf{f}=\left[\begin{array}{ll}f_{1} & f_{2}\end{array}\right]^{T}$.

Here $f$ (or $f_{1}, f_{2}$ ) are determined from the MR damper dynamics given by Eqs (3)-(7). They depend on the applied voltage which is obtained using the voltage law presented in Section 3 . The base configuration of sensors comprises an accelerometer at each storey and an LVDT to measure drift between storeys where the MR damper is attached. Thus 


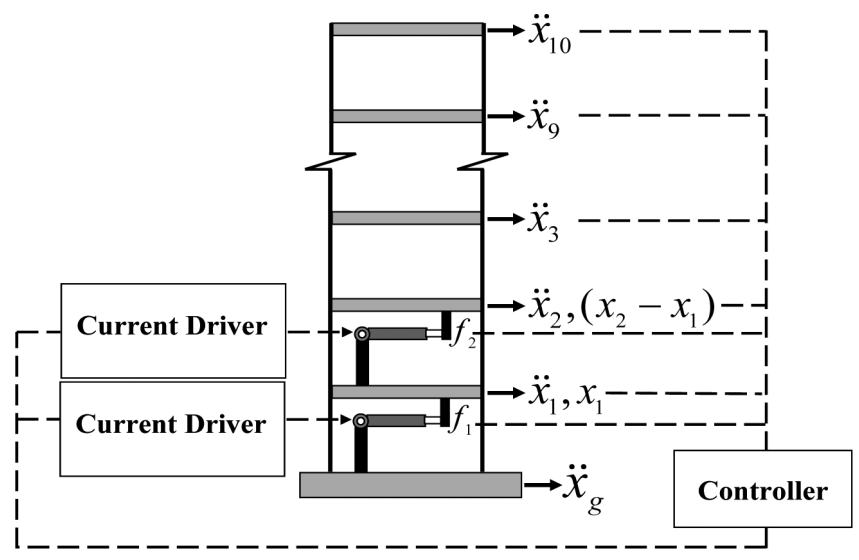

Fig. 1. Ten storey building with MR dampers and feedback controller.

output vector for base configuration of sensors with two LVDT's becomes $\mathbf{y}=\left[\begin{array}{llllll}\ddot{x}_{1} & \ddot{x}_{2} & \ldots & \ddot{x}_{10} & x_{1} & x_{2}-x_{1}\end{array}\right]^{T}$ (the last entry being absent for base configuration of sensors with one LVDT). Defining the state as $\mathbf{q}=\left[\begin{array}{ll}\mathbf{x} & \dot{\mathbf{x}}\end{array}\right]^{T}$, state and output equations for base configuration of sensors are

$$
\dot{\mathbf{q}}=\mathbf{A} \mathbf{q}+\mathbf{B} \mathbf{f}+\mathbf{E} \ddot{x}_{g} ; \quad \mathbf{y}=\mathbf{C q}+\mathbf{D} \mathbf{f}
$$

where,

$$
\begin{aligned}
& \mathbf{A}=\left[\begin{array}{cc}
\mathbf{0} & \mathbf{I} \\
-\mathbf{M}_{s}^{-1} \mathbf{K}_{s}-\mathbf{M}_{s}^{-1} \mathbf{C}_{s}
\end{array}\right] ; \mathbf{B}=\left[\begin{array}{c}
\mathbf{0} \\
\mathbf{M}_{s}^{-1} \mathbf{G}
\end{array}\right] ; \mathbf{E}=-\left[\begin{array}{c}
\mathbf{0} \\
\mathbf{L}
\end{array}\right] ; \mathbf{D}=\left[\begin{array}{c}
\mathbf{M}_{s}^{-1} \mathbf{G} \\
0
\end{array}\right]
\end{aligned}
$$

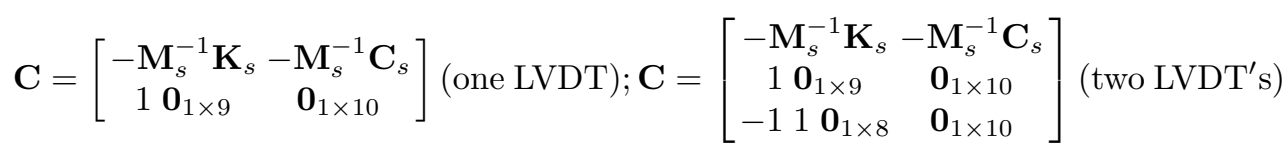

The modified Bouc-Wen MR damper model [3] is considered for the MR damper dynamics. This includes dependency of damper parameters on applied voltage $v$. The force $f$, as given by this model, is

$$
f=c_{1} \dot{y}+k_{1}\left(x-x_{0}\right)
$$

where,

$$
\begin{aligned}
& \dot{y}=\frac{1}{\left(c_{0}+c_{1}\right)}\left\{\alpha z+c_{0} \dot{x}+k_{0}(x-y)\right\} \\
& \dot{z}=-\gamma|\dot{x}-\dot{y}| z|z|^{n-1}-\beta(\dot{x}-\dot{y})|z|^{n}+A(\dot{x}-\dot{y})
\end{aligned}
$$

Here $z$ is the evolutionary (hysterisis) variable; $y$ is an internal pseudo-displacement; $x, \dot{x}$ and $f$ are the damper displacement, velocity and force, respectively. For the damper connected between ground and first storey, $x \equiv x_{1}=$ $q_{1}$ and $\dot{x} \equiv \dot{x}_{1}=q_{11}$, while for damper connected between first and second storey $x \equiv x_{2}-x_{1}=q_{2}-q_{1}$ and $\dot{x} \equiv \dot{x}_{2}-\dot{x}_{1}=q_{12}-q_{11}$. Further, $k_{1}$ is the accumulator stiffness; $x_{0}$ is the initial displacement of spring $k_{1} ; c_{0}$ and $c_{1}$ represent viscous damping at large and small velocities, respectively; $k_{0}$ is used to emulate the stiffness at large velocities; $\gamma, \beta, A$, and $n$ are hysterisis loop parameters [2]. Voltage dependency of model parameters is given as,

$$
\alpha=\alpha(u)=\alpha_{a}+\alpha_{b} u ; \quad c_{1}=c_{1}(u)=c_{1_{a}}+c_{1_{b}} u ; \quad c_{0}=c_{0}(u)=c_{0_{a}}+c_{0_{b}} u
$$

where $u$ is the output of a first order filter, i.e.,

$$
\dot{u}=-\eta(u-v)
$$

Here $v$ is the control input voltage. Model parameter values are considered from Table 2 of [3]. 
Table 1

Online computation time (sec) for semi-active controllers

\begin{tabular}{lccc}
\hline & CVL & SQVL & SOOVL \\
\hline LQG & 17.309 & 15.21 & 14.178 \\
OSOF & 0.141 & 0.171 & 0.140 \\
\hline
\end{tabular}

Table 2

Comparison of maximum peak/RMS response, base configuration of sensors, one damper, (Drift/Displ - $\mathrm{cm}$, Accel $-\mathrm{cm} / \mathrm{s}^{2}$, Force - N)

\begin{tabular}{|c|c|c|c|c|c|c|c|c|}
\hline \multirow{2}{*}{$\begin{array}{l}\text { Response } \\
\downarrow\end{array}$} & \multirow{3}{*}{$\begin{array}{l}\text { Uncont } \\
\text {-rolled }\end{array}$} & \multirow{3}{*}{$\begin{array}{c}\text { Passive } \\
\text { On }\end{array}$} & \multicolumn{3}{|c|}{ OSOF } & \multicolumn{3}{|c|}{$\overline{\mathrm{LQG}}$} \\
\hline & & & $\mathrm{CVL}$ & SQVL & SOOVL & $\mathrm{CVL}$ & SQVL & SOOVL \\
\hline$R \rightarrow$ & & & $10^{-06}$ & $10^{-06}$ & $10^{-08}$ & $10^{-06}$ & $10^{-06}$ & $10^{-06}$ \\
\hline Max RMS Drift & 1.3765 & 0.9873 & 0.7761 & 0.7741 & 0.7654 & 0.8332 & 0.8139 & 0.8036 \\
\hline Max Peak Drift & 3.617 & 2.853 & 2.4710 & 2.463 & 2.4837 & 2.777 & 2.7749 & 2.6779 \\
\hline Max RMS Displ & 8.893 & 5.9873 & 4.9061 & 4.8745 & 4.8123 & 5.3713 & 5.2475 & 5.1681 \\
\hline Max Peak Displ & 23.622 & 14.987 & 12.844 & 12.730 & 12.618 & 14.982 & 14.385 & 14.045 \\
\hline Max RMS Accel & 388.84 & 307.56 & 253.47 & 253.56 & 258.21 & 268.39 & 257.31 & 259.07 \\
\hline Max Peak Accel & 1102 & 934.5 & 1148.6 & 902.54 & 915.02 & 1273.7 & 1086.5 & 1179 \\
\hline RMS MRD Force & - & 667.19 & 509.74 & 530.84 & 527.44 & 406.39 & 437.53 & 450.94 \\
\hline Peak MRD Force & - & 1269.3 & 1309.1 & 1303.6 & 1289.6 & 1256.7 & 1252.7 & 1243.3 \\
\hline PI Semi-active & - & - & 66.84 & 67.11 & 66.7 & 73.69 & 68.12 & 69.15 \\
\hline PI Passive On & - & - & 99.04 & 99.04 & 94.64 & 99.04 & 99.04 & 99.04 \\
\hline
\end{tabular}

\section{Proposed control voltage laws}

The optimal controller (Section 4) determines the desired optimal damper force vector $\mathbf{f}_{d}$. Equations (3)-(7) show that the actual force $f$ generated by a damper is nonlinearly dependent on the state vector $\left(\mathbf{q}^{T} y z u\right)^{T}$ and voltage input to the damper. Thus the inverse problem, i.e., determining the individual voltages to be applied to a set of MR dampers so as to produce the desired control force $\mathbf{f}_{d}$ for a given state vector, is difficult to solve by conventional methods. Since only the voltage $v$ applied to an MR damper can be commanded by the controller, the desired force $\mathbf{f}_{d}$ is difficult to achieve in practice. Thus, the applied voltage is determined for each damper by the voltage control laws like SQVL, SOOVL, proposed as follows, and CVL [9]. Following Chang and Zhou [11], the limits of the evolutionary variable $z$ is given as,

$$
z_{u}= \pm\left(\frac{A}{\gamma+\beta}\right)^{\frac{1}{n}}
$$

and the stiffness terms in Eqs (3), (4) are neglected since their contribution is small compared to the damping terms. For a constant applied voltage $v$, using Eqs (3), (4), (6), (7) the bounds of the MR damper force $f$ are approximated by,

$$
f \approx \frac{\left(c_{1_{a}}+c_{1_{b}} v\right)}{\left[\left(c_{0_{a}}+c_{1_{a}}\right)+\left(c_{0_{b}}+c_{1_{b}}\right) v\right]}\left[\left(\alpha_{a}+\alpha_{b} v\right) z_{u}+\left(c_{0_{a}}+c_{0_{b}} v\right) \dot{x}\right]
$$

Substituting parameter values from Table 2 of [3] into Eq. (9), the minimum and maximum force $f_{\min }$ and $f_{\max }$ produced by the damper is obtained for applied voltage $v=0 \mathrm{~V}$ and $v=2.25 \mathrm{~V}$, respectively. For any intermediate voltage the damper force varies linearly with velocity. This is represented by a straight line lying within the realizable force region defined by the two limiting straight lines (Fig. 2). The realizable zone in the first and third quadrants are obtained for positive and negative values, respectively, of $z_{u}$. This is termed the MR constraint filter [11]. The control laws proposed herein are based on Eq. (9) from which an inverse relation is obtained between damper force and applied voltage. Equation (9) yields

$$
\begin{aligned}
& \left\{c_{1_{b}} \alpha_{b} z_{u}+c_{1_{b}} c_{0_{b}} \dot{x}\right\} v^{2}+\left\{\left(c_{1_{a}} \alpha_{b}+c_{1_{b}} \alpha_{a}\right) z_{u}+\left(c_{1_{a}} c_{0_{b}}+c_{1_{b}} c_{0_{a}}\right) \dot{x}-\left(c_{0_{b}}+c_{1_{b}}\right) f\right\} v \\
& +\left\{c_{1_{a}} \alpha_{a} z_{u}+c_{1_{a}} c_{0_{a}} \dot{x}-\left(c_{0_{a}}+c_{1_{a}}\right) f\right\}=0
\end{aligned}
$$

The required voltage for a given desired control force $f_{d}$ and velocity $\dot{x}$ can be obtained via Eq. (10). The voltage predicted using $z$ in place of $z_{u}$ in Eq. (10) would be more accurate but not implementable, as $z$ is unmeasurable. 


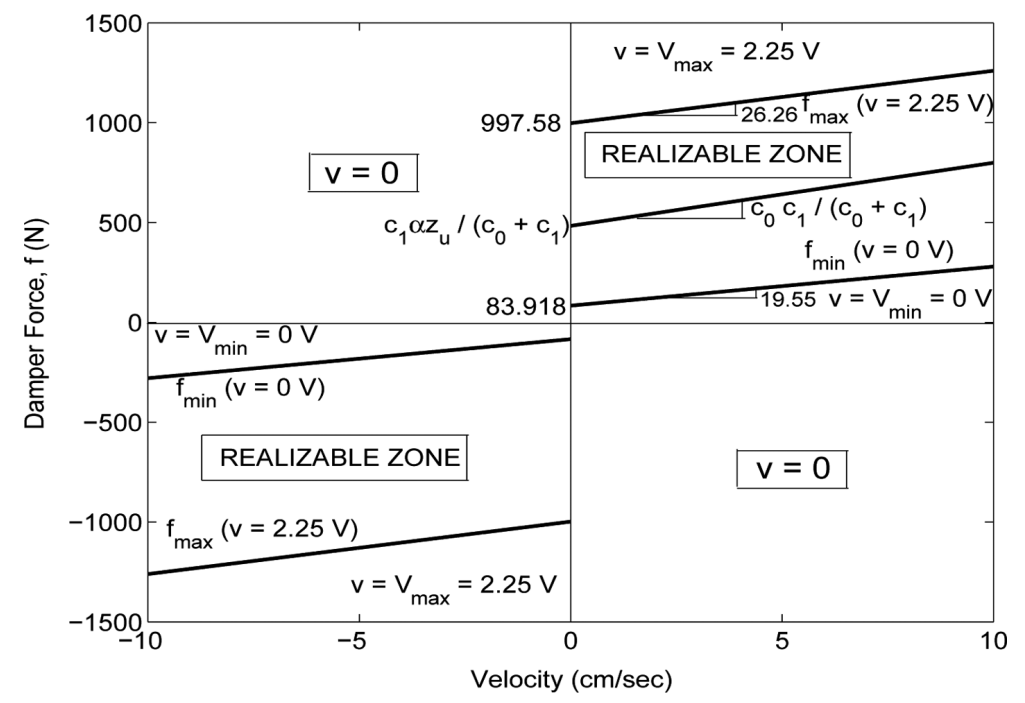

Fig. 2. Realizable zone of MR damper force in first and third quadrant of $f-\dot{x}$ plane.

Hence, $z$ is approximated as $z_{u}$ since $\operatorname{RMS}[z]$ is around $80-85 \% z_{u}$, and $z$ remains at its bounds $\pm z_{u}$ except at near-zero velocities.

The following voltage control laws are proposed, based on the MR constraint filter, in order to obtain the control voltage to be applied. These control laws are easily implementable with linear quadratic optimal control algorithms that determine the desired optimal control force (i.e., the control input) $f_{d}$ that is required to be supplied by the MR damper.

(1) Semi-inverse Quadratic Voltage Law (SQVL): If $\dot{x} f_{d}>0$ and $f_{d}$ obtained lies outside the realizable region of the MR constraint filter then the control voltage is set to the appropriate limiting value, i.e., if $\left|f_{d}\right|>\left|f_{\max }\right|$ then $v=v_{\max }=2.25 \mathrm{~V}$, else if $\left|f_{d}\right|<\left|f_{\min }\right|$ then $v=v_{\min }=0 \mathrm{~V}$. If $\dot{x} f_{d}>0$ and $f_{d}$ obtained lies within the realizable region, i.e., $\left|f_{\min }\right| \leqslant\left|f_{d}\right| \leqslant\left|f_{\max }\right|$, the control voltage is obtained from Eq. (10) by substituting $f_{d}$ for $f$, and using positive $z_{u}$ if $f_{d}>0, \dot{x}>0$ or negative $z_{u}$ if $f_{d}<0, \dot{x}<0$. If $\dot{x} f_{d}<0$ then $v=v_{\min }=$ $0 \mathrm{~V}$.

(2) Semi-inverse On-Off Voltage Law (SOOVL): This is same as SQVL except that $v=v_{\max }=2.25 \mathrm{~V}$ even when $f_{d}$ lies within the realizable zone. Thus, Eq. (10) is not required in SOOVL.

The existing Clipped Voltage Law (CVL) is considered for comparison with proposed SQVL and SOOVL. It uses $f_{d}$ and $f$ (applied damper force) in contrast to SQVL and SOOVL which use $f_{d}$ and $\dot{x}$. If $f_{d} f<0$ then $v=v_{\min }=$ $0 \mathrm{~V}$; else $v=v_{\max }=2.25 \mathrm{~V}$ when $\left|f_{d}\right|>|f|$, or $v=v_{\min }=0 \mathrm{~V}$ when $\left|f_{d}\right|<|f|$, or $v$ is held at its present value when $f_{d}=f$.

\section{Optimal static output feedback control}

State variables are often not measurable for feedback. One way to design the controller in such situations is to design an observer (i.e., state estimator) and then use observer based feedback. LQG control [18] uses the measured output and control input to estimate the states which are then fed back, i.e., the control input is obtained from the estimated states. It involves state estimation via a Kalman filter which minimizes estimation error. Alternatively, the controller design can be done without state estimation, i.e., by obtaining the desired control input (MR damper force in this case) via measured output feedback instead of state feedback. This is termed LQR (Linear Quadratic Regulator) with Output Feedback or Optimal Static Output Feedback Control (OSOF). It has the advantage of fewer on-line computations as compared to LQG control. OSOF control is briefly described as follows [18].

The state equations representing system dynamics, the desired damper force, i.e., control input $\mathbf{f}_{d}$ obtained by output feedback, and the measured output $\mathbf{y}$, are given by, 


$$
\dot{\mathbf{q}}=\mathbf{A} \mathbf{q}+\mathbf{B} \mathbf{f}_{d} ; \quad \mathbf{f}_{d}=-\mathbf{K} \mathbf{y} ; \quad \mathbf{y}=\mathbf{C q}
$$

where $\mathbf{K}$ is the matrix of constant feedback gains to be determined. In OSOF regulator design, $\mathbf{K}$ (hence $\mathbf{f}_{d}$ ) is determined so as to minimize the quadratic Performance Index (PI) $J^{*}=\frac{1}{2} \int_{0}^{\infty}\left[\mathbf{q}^{T} \mathbf{Q} \mathbf{q}+\mathbf{f}_{d}^{T} \mathbf{R} \mathbf{f}_{d}\right] \mathrm{d} t$, where $\mathbf{Q}$ is the positive semi-definite state weighting matrix and $\mathbf{R}$ is the positive definite control input weighting matrix. In general, if the controller is effective for random initial conditions it is also effective for random input excitations [19]. Considering an asymptotically stable closed loop system $(\mathbf{q} \rightarrow \mathbf{0}$ as $t \rightarrow \infty)$, it can be shown that $J^{*}=\frac{1}{2} \operatorname{tr}(\mathbf{P} \tilde{\mathbf{Q}})$ where $\tilde{\mathbf{Q}}=E\left\{\mathbf{q}(0) \mathbf{q}^{T}(0)\right\}$ — the initial autocorrelation of the state [20]. The minimization of $J^{*}$ yields the design equations [18]:

$$
\begin{aligned}
& \mathbf{A}_{c}^{T} \mathbf{P}+\mathbf{P} \mathbf{A}_{c}+\mathbf{C}^{T} \mathbf{K}^{T} \mathbf{R K C}+\tilde{\mathbf{Q}}=\mathbf{0} \\
& \mathbf{A}_{c} \mathbf{S}+\mathbf{S A}_{c}^{T}+\tilde{\mathbf{Q}}=\mathbf{0} \\
& \mathbf{R}^{-1} \mathbf{B}^{T} \mathbf{P S C}^{T}\left(\mathbf{C S C}^{T}\right)^{-1}=\mathbf{K}
\end{aligned}
$$

Here $\mathbf{A}_{c}=\mathbf{A}-\mathbf{B K C}$ is the closed loop system matrix. Equations (12) and (13) are Lyapunov equations in unknowns $\mathbf{P}$ (symmetric, positive semi-definite) and $\mathbf{S}$ (matrix of Lagrange multipliers), respectively, and Eq. (14) gives the optimal gain $\mathbf{K}$. Assuming uncorrelated initial states, i.e., $\tilde{\mathbf{Q}}=\mathbf{I}$, where $\mathbf{I}$ is the identity matrix, the optimal cost becomes $E\left[J^{*}\right]=J=\frac{1}{2} \operatorname{tr}[\mathbf{P}]$. Equations (12)-(14) are solved using the Moerder-Calise algorithm [21], as follows:

Step (1): Initialization: Iteration counter $k=0$. Select initial output feedback gain $\mathbf{K}_{0}$ so that $\mathbf{A}_{c}$ is asymptotically stable. If open loop plant is stable $\mathbf{K}_{0}=\mathbf{0}$ can be the choice.

Step (2): $\mathbf{A}_{k} \longleftarrow\left(\mathbf{A}-\mathbf{B K}_{k} \mathbf{C}\right), \mathbf{A}_{c} \longleftarrow \mathbf{A}_{k}, \mathbf{K} \longleftarrow \mathbf{K}_{k}$. Solve Eqs (12), (13) for $\mathbf{P}$ and $\mathbf{S}$. Then $\mathbf{P}_{k} \longleftarrow \mathbf{P}$, $\mathbf{S}_{k} \longleftarrow \mathbf{S}, J_{k}=\frac{1}{2} \operatorname{tr}\left[\mathbf{P}_{k}\right]$. If $k>0$ and $\left|J_{k}-J_{k-1}\right|<\varepsilon$, where $\varepsilon$ is a small tolerance, algorithm has converged, go to Step 4 .

Step (3): $\mathbf{K}_{k+1} \longleftarrow \mathbf{K}_{k}+\alpha \Delta \mathbf{K}$, where $\Delta \mathbf{K}=\mathbf{R}^{-1} \mathbf{B}^{T} \mathbf{P}_{k} \mathbf{S}_{k} \mathbf{C}^{T}\left(\mathbf{C S}_{k} \mathbf{C}^{T}\right)^{-1}-\mathbf{K}_{k}$ and $\alpha$ is chosen : $\mathbf{A}_{k+1}$ is asymptotically stable where $\mathbf{A}_{k+1} \longleftarrow\left(\mathbf{A}-\mathbf{B} \mathbf{K}_{k+1} \mathbf{C}\right) . k \longleftarrow k+1$. Go to Step (2).

Step (4): $\mathbf{K}=\mathbf{K}_{k}$

In the presence of a feed-through (i.e., direct transmission) term $\mathbf{D} \mathbf{f}_{d}$, as in the present case, the measured output and the control input (i.e., desired damper force obtained via output feedback) are

$$
\hat{\mathbf{y}}=\mathbf{C q}+\mathbf{D} \mathbf{f}_{d} ; \quad \mathbf{f}_{d}=-\mathbf{K} \hat{\mathbf{y}}
$$

from which one obtains

$$
\mathbf{f}_{d}=-\hat{\mathbf{K}} \mathbf{y} \quad \text { where } \hat{\mathbf{K}}=(\mathbf{I}+\mathbf{K D})^{-1} \mathbf{K}
$$

Equation (16) is equivalent to Eq. (11b) with $\mathbf{K}$ replaced by $\hat{\mathbf{K}}$. The optimal feedback gain $\hat{\mathbf{K}}$ can be obtained by the Moerder-Calise algorithm. Subsequently, the feedback gain $\mathbf{K}$ is obtained as

$$
\mathbf{K}=\hat{\mathbf{K}}(\mathbf{I}-\mathbf{D} \hat{\mathbf{K}})^{-1}
$$

for use in actual implementation in the controller. Previous implementations of OSOF control do not consider the feed-through term [15]. Hence they are restricted to measured outputs being combinations of states alone, i.e., desired control force is obtained from displacement and velocity feedback only. Since the feed-through term is considered herein, in a practical implementation the desired control force can be obtained using acceleration feedback also, as done here.

The block diagram for the physical implementation of OSOF control algorithm is shown in Fig. 3. Thus, the structure and MR damper equations (comprising the plant) are integrated using the available applied voltage and states at the start of each time step. The states are thus obtained, and actual applied damper force $f$ computed via Eq. (3), at the end of each time step. Measured outputs are thus obtained via Eq. (15a) and fed to the controller which computes the desired damper force, $f_{d}$, via the output feedback control Eq. (11b). The velocities of dampers, equivalently denoted as $\dot{x}_{1} \equiv q_{11}$ and $\dot{x}_{2}-\dot{x}_{1} \equiv q_{12}-q_{11}$ where applicable, are also obtained from computed states. Thus, the damper velocities, and $f, f_{d}$, are fed to any of the control voltage laws (SOOVL, SQVL, CVL) to obtain the voltage to be applied to the damper at the start of the next time step. Although the velocity of each damper is a measured output, it is not included in $\mathbf{y}$ as it is not used to obtain $f_{d}$ herein (i.e., it is neither used in the estimator design in LQG control nor in the output feedback part of OSOF control). However, this does not preclude it from being part of $\mathbf{y}$ in future applications. 


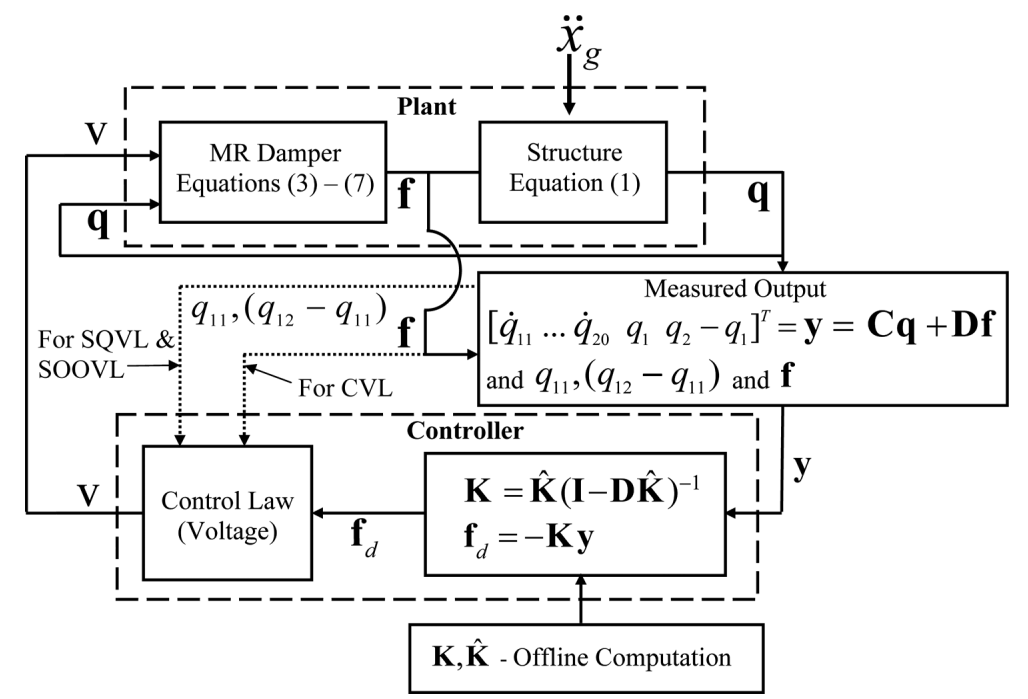

Fig. 3. Implementation of optimal static output feedback control algorithm.

\section{Results and discussions}

The following cases are considered:

(1) Passive Control: For passive-off case damper voltage applied is $v=0 \mathrm{~V}$. For passive-on case the damper force saturation voltage $v=2.25 \mathrm{~V}$ is applied.

(2) Semi-active Control: Desired control force $\mathbf{f}_{d}$ (i.e., control input vector) is determined using either OSOF or LQG control method. Then voltage applied to the damper is obtained, using $\mathbf{f}_{d}$, via either of the voltage laws (i.e., SQVL, SOOVL and CVL). If voltage law is not specified with the control method it is implied that the result pertains to any of the three voltage laws used with the particular control method.

Structural properties given in [13] are considered herein for the system model used in controller design. Nominal mass of each floor is $m_{i}=50 \mathrm{~kg}, i=1, \ldots 10$. Interstorey stiffnesses $k_{i}, i=1, \ldots 10$, are 948.70, 836.99, 886.11, $889.33,925.77,881.83,833.79,824.03,872.11$ and $829.86 \mathrm{~N} / \mathrm{cm}$ for first to tenth storey, respectively. Rayleigh damping coefficients are considered as $\alpha_{m}=0.1 \mathrm{~s}^{-1}$ and $\alpha_{k}=7.36 \times 10^{-4} \mathrm{~s}$. Damper parameters in Table 2 of [3] are considered, except that initial offset due to the accumulator is neglected, i.e., $x_{0}=0$ [9]. Unless mentioned otherwise, the structure is subjected to N-S component of EL Centro (1940) ground acceleration data measured at Imperial Valley [22]. All controlled responses were observed to be sufficiently attenuated at $10 \mathrm{~s}$, and their peaks were observed to occur well before $10 \mathrm{~s}$. Hence, response for first $10 \mathrm{~s}$ of earthquake excitation is considered here, which appears sufficient for comparing across controllers.

The first-order ODE's (Eqs (4), (5), (7)) pertaining to MR damper and the state equations pertaining to structural system dynamics (Eq. (1)) are simultaneously solved using MATLAB module ODE45. Initial conditions are $\mathbf{q}(0)=\mathbf{0}$ (structure at rest), $u(0)=0$ (no applied voltage), $z(0)=0$ (no hysterisis component), and $y(0)=0$, yielding $f(0)=0$ (zero initial force in damper). Response quantities (interstorey drift - $\mathrm{cm}$, displacement - $\mathrm{cm}$, acceleration $-\mathrm{cm} / \mathrm{s}^{2}$, and MR damper force $-\mathrm{N}$ ) are obtained at time interval $\Delta t=0.02 \mathrm{~s}$.

\subsection{Building with one MR damper}

Here $\mathbf{R}=[R]$ since the control input (vector of damper forces) is a scalar. For easy comparison, the PI for passive-on control is determined using the respective $\mathbf{Q}$ and $\mathbf{R}$ of the semi-active controller with which it is compared. Table 1 compares online computation time for OSOF and LQG controllers. The values of $\mathbf{Q}$ and $R$ are same as considered in Table 2. Both semi-active controllers involve feedback and control voltage computations, while LQG control involves estimation of observer dynamics in addition to these computations. Hence, as expected, the computation time required for LQG is greater (by two orders of magnitude) than OSOF. 


\subsubsection{Base configuration of sensors - Peak and RMS response}

The OSOF controllers are compared with passive and LQG controllers in Table 2 for maximum peak/RMS responses (drift, displacement, acceleration), peak/RMS damper force, and PI. The maximum value is taken across all storeys and the peak value is across the duration of earthquake record considered. The base configuration of sensors is considered. This measures ten accelerations and one interstorey drift of the first storey (relative to ground) where damper is attached, and is denoted (10A,1ID). Accelerometers provide inexpensive and reliable measurements of acceleration, without requiring an inertial reference as compared to displacement and velocity sensors [9]. For low frequency structures (as in civil engineering) LVDT sensors can be employed to accurately measure interstorey drift [15]. State weighting Q (Eq. (4)) is chosen to weight top storey acceleration only, i.e, $\mathbf{Q}=\mathbf{C}^{T} \hat{\mathbf{Q}} \mathbf{C}, \hat{\mathbf{Q}}=\operatorname{diag}[\mathbf{0} 1]$. The value of $R$ indicated for semi-active controllers corresponds to the most effective control for the particular combination of control method and voltage law indicated in Table 2. Passive-off control results are omitted since it is less effective.

When comparing passive-on control with uncontrolled response (i.e., without MR damper), the reduction in maximum peak/RMS drift, displacement, and acceleration, is substantial (15\%-36\%). We see that OSOF control achieves substantial reduction $(>12 \%)$ of interstorey drift and displacement as compared to passive-on control. Considerable $(>16 \%)$ reduction over passive-on response also occurs in maximum RMS acceleration when using OSOF. However, the maximum peak acceleration reduces only marginally $(<3.4 \%)$, and for OSOF-CVL it is in fact substantially higher $(22.91 \%)$.

Peak damper forces generated are marginally $(<5.3 \%)$ higher when using OSOF control compared to passiveon/LQG control. Corresponding RMS damper forces are considerably ( $>20 \%$ ) lower compared to passive-on control, but considerably (up to 31\%) higher vis-a-vis LQG control. However, lowest PI results from OSOF control as compared to passive-on/LQG control, proving the efficacy of this control method. For OSOF control, the performance of newly proposed control voltage laws (SOOVL, SQVL) is comparable to the existing CVL. OSOFSOOVL control yields marginally lower maximum peak/RMS displacement as well as maximum RMS interstorey drift as compared to OSOF-SQVL/OSOF-CVL.

In comparison to passive-on control, LQG affords marginal to substantial (up to 18\%) attenuation of maximum peak/RMS responses with the exception of maximum peak acceleration (for which the increase is up to 36\%). Peak damper forces are marginally $(<2 \%)$ lower, while RMS damper forces are substantially $(>32 \%)$ lower, for LQG compared to passive-on control. LQG yields lower PI compared to passive-on control. Thus, both semi-active controllers perform better than passive-on control, since yielding of MR fluid is controlled instead of occurring at constant stress level.

When comparing OSOF with LQG control, the former yields up to $22 \%$ reduction in maximum peak/RMS values of all responses. Thus, OSOF control, with one MR damper, is quite effective for response attenuation as compared to passive-on/LQG control. The proposed control voltage laws SQVL and SOOVL (based on MR constraint filter) yield marginally better maximum peak/RMS responses than existing CVL when using LQG, and are comparable to CVL when using OSOF control. Thus they prove quite effective.

Among semi-active controllers, OSOF-SOOVL yields the lowest PI, and SOOVL controllers yield best performance in terms of drift and displacement. Hence, OSOF-SOOVL and LQG-SOOVL are chosen for storeywise comparisons with passive-on controller, for peak/RMS responses. Figure 4 compares storeywise interstorey drift. Maximum peak interstorey drift occurs at second storey. Although passive-on control is most effective in reducing peak as well as RMS interstorey drift at the first storey (where MR damper is installed), it proves less effective for the remaining storeys where both semi- active controllers perform substantially better. This occurs since passive on control causes the damper to yield at a constant value of shear, thus making the damper storey behave rigid (relative to other storeys) and vibration energy to be transferred to other storeys. On the other hand the semi-active controllers strive to minimize the system PI, which results in application of variable voltage and hence variable yield stress for the damper, thus distributing the vibratory energy across the structure. The maximum peak/RMS response is lowest for OSOF-SOOVL (also see Table 2). Reduction in peak interstorey drift for storeys 1 to 5 is considerable when using OSOF-SOOVL control compared to LQG-SOOVL, while both semi-active controllers yield near identical results for storeys 6 to 10. Reduction in RMS interstorey drift is substantial for first storey and marginal for storeys 2 to 6 when using OSOF-SOOVL control compared to LQG-SOOVL, while both semi- active controllers yield near identical results for storeys 7 to 10 . 

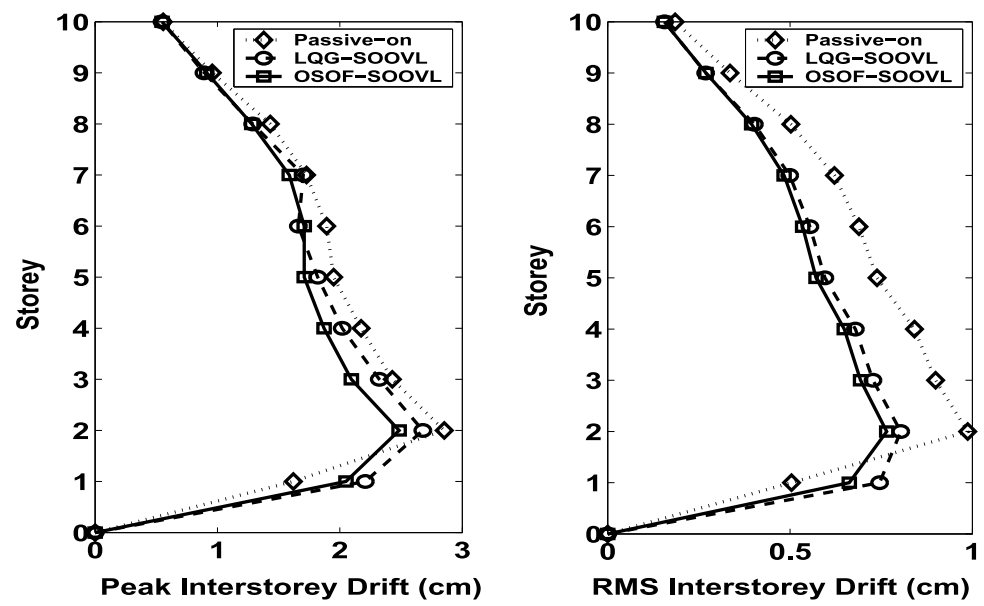

Fig. 4. Storeywise peak and RMS inter-storey drifts.
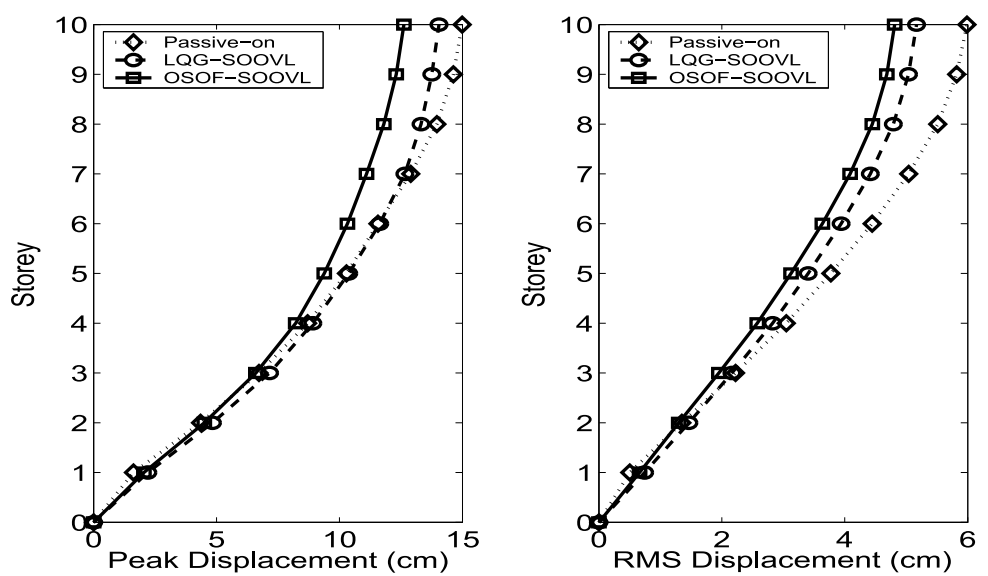

Fig. 5. Storeywise peak and RMS displacements.

Figure 5 compares storeywise displacement. Maximum peak/RMS displacements occur for top storey. OSOFSOOVL control yields a reduction in peak/RMS displacement vis-a-vis passive-on and LQG-SOOVL responses, except at first storey (where damper is attached) for which, as noted earlier, passive-on control is marginally better. This reduction becomes increasingly prominent at higher storeys. This clearly shows the efficacy of OSOF-SOOVL over LQG-SOOVL and passive-on controllers. Peak displacements using LQG-SOOVL and passive-on are near identical for storeys 1 to 7, with LQG-SOOVL yielding a moderate reduction for storeys 8 to 10. RMS displacements using LQG-SOOVL and passive-on are near identical for storeys 1 to 3, with LQG yielding a substantial reduction for storeys 4 to 10 .

Figure 6 compares storeywise acceleration. The uncontrolled response is also shown since it is comparable or lower than some of the controlled responses at certain storeys. Maximum peak/RMS acceleration occurs at top storey, except for LQG-SOOVL for which the peak occurs at storey 5. Compared to uncontrolled response, passive-on control shows substantial reduction in peak accelerations at storeys 6 to 10. Compared to uncontrolled and passive-on control, the semi-active acceleration responses are substantially higher at the first storey (where damper is attached). This occurs since the top storey acceleration is weighted in the PI. Peak accelerations from OSOF-SOOVL, as compared to passive-on/uncontrolled case, are somewhat higher at storeys 2 to 4, and comparable/substantially-lower at higher storeys. Peak acceleration from OSOF-SOOVL, as compared to LQG-SOOVL, is lower for all storeys (in fact considerably so, except for second and top storey). Note that LQG-SOOVL is least effective in controlling peak accelerations. In fact although the PI weights top storey accelerations, the large peak acceleration at the damper 

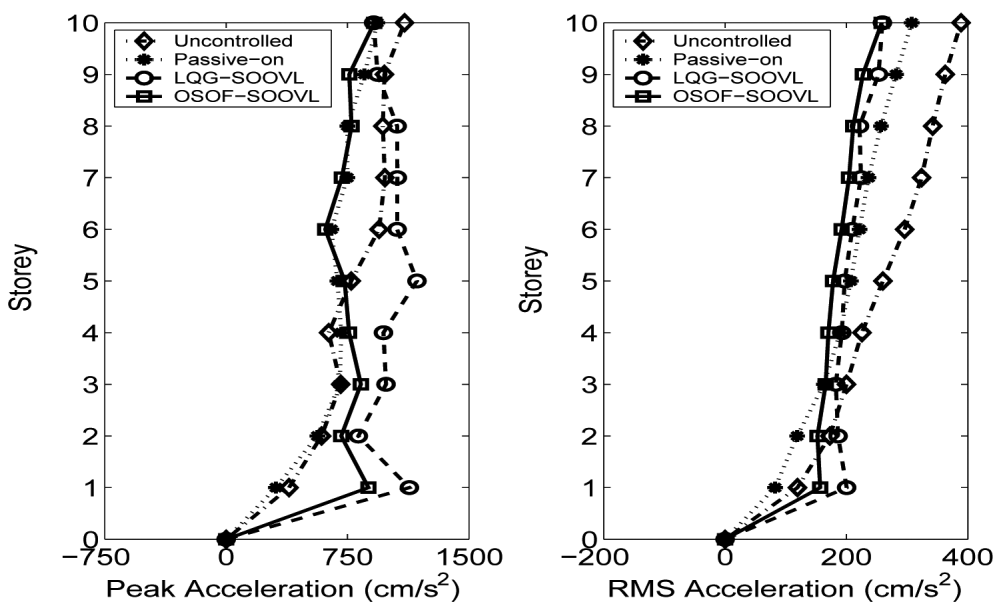

Fig. 6. Storeywise peak and RMS accelerations.
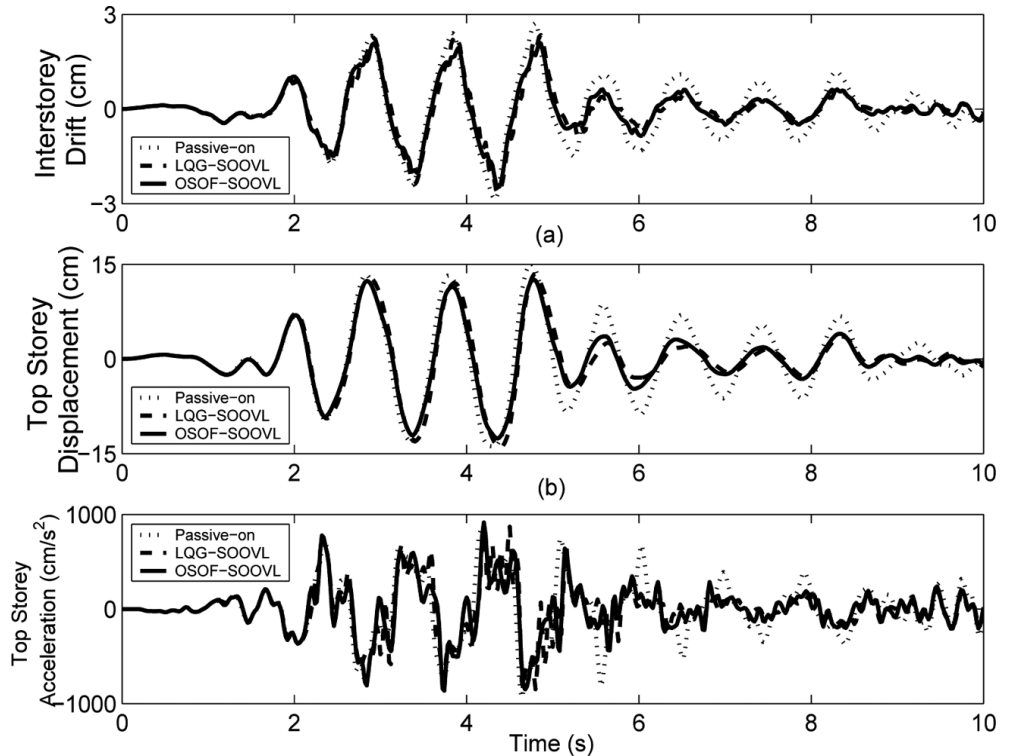

(c)

Fig. 7. Time histories (a) Second storey interstorey drift; Top storey (b) displacement, (c) acceleration.

storey, resulting due to this weighting, does not exceed top storey peak acceleration in case of OSOF-SOOVL. However in case of LQG-SOOVL the peak accelerations at all storeys (except second) exceed that at the top storey, thus resulting in a higher maximum peak acceleration due to this weighting. The RMS acceleration response shows that all controllers are substantially more effective than the uncontrolled system, with OSOF-SOOVL control being most effective.

\subsubsection{Base configuration of sensors - Time history}

The $\mathbf{Q}$ and $\mathbf{R}$ weights are same as in Section 5.1.1, and time traces of OSOF-SOOVL, LQG-SOOVL, and passive-on control are compared. Figure 7(a) shows time trace of interstorey drift for the storey where maximum peak interstorey drift occurs, i.e., second storey for all three controllers. It is clear that OSOF-SOOVL yields lowest peak interstorey drift (which occurs around $4.34 \mathrm{~s}$ for all controllers).

Figure 7(b) shows time trace of top storey displacement. The peak displacement occurs earlier for both semiactive controllers (around $4.37 \mathrm{~s}$ compared to $4.74 \mathrm{~s}$ for passive-on control). It is evident that OSOF-SOOVL yields 

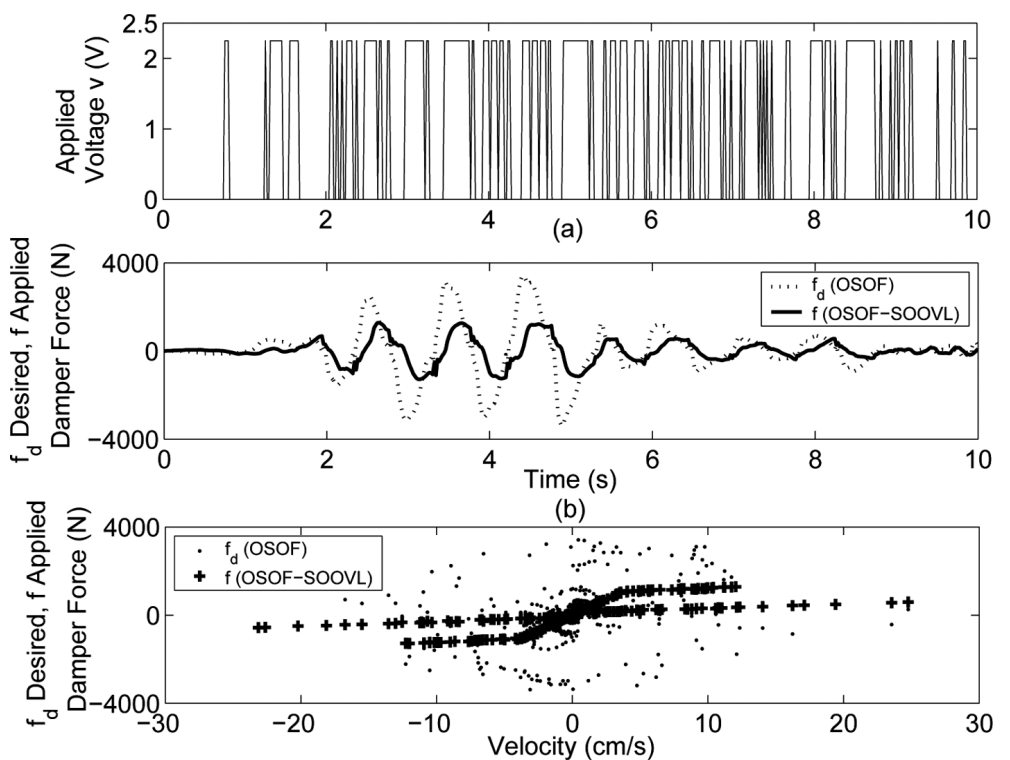

(c)

Fig. 8. (a,b) Time histories (a) Applied voltage (b) Desired, Applied- damper force; (c) Desired, Applied -damper force versus velocity.

lowest peak displacement. Figure 7(c) shows time trace of accelerations for top storey. As expected, both semiactive controllers generally yield lower accelerations (see especially $t>4.6$ ), due to top storey acceleration being weighted in the PI. They also yield marginally lower peak accelerations (911-LQG-SOOVL, 915-OSOF-SOOVL, 934-Passive-on, see also Fig. 6(a)).

Figure 8(a) shows time trace of voltage applied to the damper when using OSOF-SOOVL control. The voltage switches between $0 \mathrm{~V}$ and $2.25 \mathrm{~V}$ (saturation level), remaining saturated for $57.4 \%$ of total simulation time shown. This implies a power savings when using OSOF vis-a-vis passive-on control, apart from superior control noted earlier. Desired and applied damper forces are compared in Figs 8(b) and (c) where they are shown versus time and versus relative velocity (of damper), respectively. Differences between applied and desired damper forces are apparent. Figure 8(c) clearly shows that the applied damper force lies in first and third quadrants (a behavior that is inherent in the damper constitutive law), whereas desired damper force (obtained from the optimal controller) lies in all quadrants. This difference is due to three reasons: firstly the inverse dynamics of the damper (i.e., prediction of applied voltage for given force) is difficult to obtain, due to which the SOOVL has been considered in order to obtain the voltage approximately; secondly the damper force saturates at $v=2.25 \mathrm{~V}$, which limits the maximum force that the damper can produce; and thirdly due to the constitutive law that restricts force-velocity to lie in first and third quadrants. The RMS of difference between desired and applied damper forces is $971.46 \mathrm{~N}$.

\subsubsection{Parametric studies - Peak and RMS response}

Section 5.1.1 shows that a considerable reduction in maximum peak/RMS response is afforded by OSOF compared to passive-on or LQG control for the base configuration of sensors. Various other sensor configurations (considering type of output measured, numbers, placement), state weighting $\mathbf{Q}$, and control weighting $\mathbf{R}$ are now considered in order to explore the possibility of better control and/or more efficient sensor usage (i.e., numbers, placement). As before, accelerations and interstorey drifts are measured. Sensors are spread across the structure in order to obtain a global measurement of response (i.e., output) to be fedback via the controller. Table 3 shows the sensor configurations considered ((10A,1ID) being base configuration of sensors considered in Section 5.1.1). State weighting $\mathbf{Q}$, pertaining to various alternative weightings of response quantities as considered in the PI (Eq. (4)), is given in Table 4.

Results obtained for the various sensor configurations considered are compared in Table 5 for maximum peak/RMS responses, PI, and peak/RMS damper force. For each sensor configuration, results for the controller (comprising control method, voltage law, state weighting $\mathbf{Q}$ and $R$ ) yielding most effective control is reported. Quantities in 
Table 3

Sensor configurations with one damper

\begin{tabular}{|c|c|c|c|c|c|c|c|c|c|}
\hline \multirow{3}{*}{$\begin{array}{c}\text { Storey } \\
\text { No. }\end{array}$} & \multicolumn{9}{|c|}{ Sensor Configuration } \\
\hline & \multicolumn{9}{|c|}{ (० Accelerometer } \\
\hline & $10 \mathrm{~A}, 1 \mathrm{ID}$ & $5 \operatorname{ID}(1)$ & 10ID & 10A, 10ID & $3 \mathrm{~A}, 1 \mathrm{ID}$ & $3 \mathrm{~A}, 3 \mathrm{ID}$ & $10 \mathrm{~A}$ & $5 \mathrm{~A}$ & $5 \operatorname{ID}(2)$ \\
\hline 10 & 0 & & $\bar{x}$ & $0 \times$ & 0 & 0 & 0 & o & $\bar{x}$ \\
\hline 9 & ० & $\times$ & $\times$ & $\circ \times$ & & & ० & & \\
\hline 8 & ० & & $x$ & $\circ \times$ & & o & ० & $\circ$ & $x$ \\
\hline 7 & ० & $x$ & $x$ & $\circ \times$ & $\circ$ & & ० & & \\
\hline 6 & ० & & $x$ & $\circ \times$ & & $\circ$ & ० & & $\times$ \\
\hline 5 & ० & $x$ & $x$ & $\circ \times$ & & $x$ & ० & & \\
\hline 4 & ० & & $x$ & $\circ \times$ & ० & & ० & & $x$ \\
\hline 3 & ० & $x$ & $x$ & $\circ \times$ & & $x$ & ० & ० & \\
\hline 2 & ० & & $x$ & $\circ \times$ & & & o & ० & $x$ \\
\hline 1 & $\circ \times$ & $\times$ & $\times$ & $0 \times$ & $\times$ & $\times$ & $\circ$ & $\circ$ & \\
\hline
\end{tabular}

Table 4

Response quantities weighted in PI and corresponding state weighting matrix $\mathbf{Q}$

\begin{tabular}{cll}
\hline Notation & Response being weighted & \multicolumn{1}{|}{$\mathbf{Q}$} \\
\hline$Q_{1}$ & Top storey Acceleration & $\mathbf{C}^{\mathbf{T}} \hat{\mathbf{Q}}, \hat{\mathbf{Q}}=\operatorname{diag}[\mathbf{0} 1]$ \\
$Q_{2}$ & Total energy of system & $\operatorname{diag}\left[\mathbf{K}_{s} \mathbf{M}_{s}\right]$ \\
$Q_{3}$ & Top storey Displacement & $\mathbf{0}$ except $\mathbf{Q}_{10,10}=1$ \\
$Q_{4}$ & Bottom storey Interstorey Drift & $\mathbf{0}$ except $\mathbf{Q}_{1,1}=\mathbf{Q}_{10,10}=1$ \\
& and top storey Displacement & \\
\hline
\end{tabular}

Table 5

Maximum peak/RMS response for various sensor configurations, one damper, (Drift/Displ $-\mathrm{cm}$, Accel $-\mathrm{cm} / \mathrm{s}^{2}$, Force - N)

\begin{tabular}{lcccccccc}
\hline SensorConfig $\rightarrow$ & 5ID $(1)$ & 10ID & 10A,10ID & 3A,1ID & 3A,3ID & 10A & 5A & 5ID(2) \\
\hline Response & OSOF & OSOF & OSOF & LQG & LQG & LQG & LQG & Passive \\
$\downarrow$ & SOOVL & SOOVL & SQVL & CVL & SOOVL & SQVL & SOOVL & On \\
& $Q_{2}$ & $Q_{3}$ & $Q_{2}$ & $Q_{3}$ & $Q_{2}$ & $Q_{2}$ & $Q_{2}$ & $10^{-09}$ \\
\hline \multicolumn{1}{c}{$R \rightarrow$} & $10^{-07}$ & $10^{-11}$ & $10^{-06}$ & $10^{-09}$ & $10^{-06}$ & $10^{-11}$ & $10^{-09}$ \\
\hline Max RMS Drift & 0.7826 & 0.7893 & 0.7785 & 0.7992 & 0.7898 & 0.7845 & 0.7822 & 0.9873 \\
& {$[-17.6]$} & {$[-7.34]$} & {$[-0.80]$} & {$[8.31]$} & {$[-0.77]$} & {$[-7.81]$} & {$[-27.7]$} & {$[12.2]$} \\
Max Peak Drift & 2.4965 & 2.498 & 2.2494 & 2.2483 & 2.4052 & 2.2592 & 2.2873 & 2.853 \\
& {$[-20.7]$} & {$[-17.7]$} & {$[-0.47]$} & {$[-18.7]$} & {$[-2.50]$} & {$[-24.7]$} & {$[-29.9]$} & {$[-7.38]$} \\
Max RMS Displ & 4.9001 & 4.9431 & 4.8646 & 4.9879 & 4.9448 & 4.9039 & 4.8912 & 5.9873 \\
& {$[-20.6]$} & {$[-9.79]$} & {$[-0.84]$} & {$[5.98]$} & {$[-0.56]$} & {$[-8.51]$} & {$[-30.4]$} & {$[7.74]$} \\
Max Peak Displ & 12.717 & 12.781 & 12.750 & 12.969 & 12.872 & 12.829 & 12.796 & 14.987 \\
& {$[-32.2]$} & {$[-18.6]$} & {$[-0.65]$} & {$[0.57]$} & {$[0.41]$} & {$[-14.0]$} & {$[-35.9]$} & {$[-12.4]$} \\
Max RMS Accel & 268.54 & 266.43 & 254.20 & 257.68 & 262.46 & 249.42 & 252.02 & 307.56 \\
& {$[-15.2]$} & {$[-1.83]$} & {$[1.89]$} & {$[0.75]$} & {$[-1.32]$} & {$[-13.0]$} & {$[-16.9]$} & {$[-0.94]$} \\
Max Peak Accel & 1101.8 & 1028.5 & 992.76 & 921.01 & 969.48 & 903.82 & 950.42 & 934.5 \\
& {$[-7.29]$} & {$[5.51]$} & {$[9.82]$} & {$[-13.0]$} & {$[-4.27]$} & {$[-30.9]$} & {$[1.73]$} & {$[-24.8]$} \\
RMS MRD Force & 543.04 & 549.31 & 548.85 & 558.27 & 547.88 & 548.38 & 542.31 & 667.19 \\
Peak MRD Force & 1273.5 & 1295.6 & 1316.0 & 1300.6 & 1305.1 & 1315.9 & 1314.7 & 1269.3 \\
PI Semi-active & 560.63 & 0.02446 & 549.80 & 0.0280 & 568.31 & 554.07 & 552.21 & - \\
PI Passive On & 819.32 & 0.03589 & 823.33 & 0.0403 & 823.33 & 818.88 & 818.88 & - \\
\hline
\end{tabular}

square brackets denote percentage change when compared and normalized with the most effective complimentary controller, i.e., if the most effective controller is based on OSOF then, using the same sensor configuration, the most effective complimentary controller is based on LQG, and vice-versa. The sensor configurations and corresponding most effective complimentary controller are: (5ID $(1)) \rightarrow\left(\right.$ LQG-SOOVL, $\left.Q_{3}, R=10^{-17}\right)$; (10ID) $\rightarrow$ (LQG-SQVL, $\left.Q_{1}, R=10^{-11}\right)$; (10A,10ID) $\rightarrow\left(\right.$ LQG-SQVL $\left., Q_{2}, R=10^{-09}\right)$; (3A,1ID) $\rightarrow\left(\right.$ OSOF-SOOVL $\left., Q_{1}, R=10^{-15}\right)$; $(3 \mathrm{~A}, 3 \mathrm{ID}) \rightarrow\left(\right.$ OSOF-SOOVL, $\left.Q_{1}, R=10^{-07}\right)$; (10A) $\rightarrow$ (OSOF-SOOVL, $\left.Q_{1}, R=10^{-09}\right)$; (5A) $\rightarrow$ (OSOF-CVL, $\left.Q_{1}, R=10^{-05}\right)$. For sensor configuration ( $\operatorname{IID}(2)$ ), passive-on control is most effective, and hence the most effective complimentary controller is also the most effective semi-active controller, i.e., (OSOF-SQVL, $Q_{3}, R=10^{-17}$ ). 
Table 6

Comparison of OSOF with robust reliability-based control of [13], (Drift/Displ - cm, Accel - g, Force - N)

\begin{tabular}{|c|c|c|c|c|c|c|c|c|}
\hline $\begin{array}{l}\text { Max Peak } \\
\text { Response }\end{array}$ & $\begin{array}{l}\text { Contr-A } \\
\text { (present) }\end{array}$ & $\begin{array}{l}\text { Contr-B } \\
\text { (present) }\end{array}$ & $\begin{array}{c}\text { Contr-1 } \\
{[13]} \\
\end{array}$ & $\begin{array}{c}\text { Contr-2 } \\
{[13]}\end{array}$ & $\begin{array}{r}\text { Contr-A } \\
\text { (present) }\end{array}$ & $\begin{array}{l}\text { Contr-B } \\
\text { (present) }\end{array}$ & $\begin{array}{c}\text { Contr-1 } \\
{[13]}\end{array}$ & $\begin{array}{c}\text { Contr-2 } \\
{[13]} \\
\end{array}$ \\
\hline & \multicolumn{4}{|c|}{$50 \%$ El Centro earthquake } & \multicolumn{4}{|c|}{$100 \%$ El Centro earthquake } \\
\hline Drift & 0.6838 & 0.7259 & 0.663 & 0.664 & 1.4188 & 1.4211 & 1.360 & 1.359 \\
\hline Displ & 4.5075 & 4.1165 & 4.542 & 4.453 & 8.9738 & 8.3056 & 9.082 & 8.972 \\
\hline Accel & 0.422 & 0.491 & 0.436 & 0.451 & 0.853 & 0.971 & 0.850 & 0.907 \\
\hline \multirow[t]{2}{*}{ MRD Force } & 775.46 & 760.47 & 751 & 808 & 1280.1 & 1241.0 & 1270 & 1276 \\
\hline & \multicolumn{4}{|c|}{$150 \%$ El Centro earthquake } & \multicolumn{4}{|c|}{$50 \%$ Kobe earthquake } \\
\hline Drift & 2.2021 & 2.4939 & 2.203 & 2.186 & 2.7851 & 3.0173 & 3.030 & 3.005 \\
\hline Displ & 14.661 & 15.396 & 14.92 & 14.67 & 18.734 & 18.580 & 19.14 & 18.99 \\
\hline Accel & 1.194 & 1.315 & 1.199 & 1.295 & 1.007 & 1.007 & 0.993 & 1.018 \\
\hline MRD Force & 1483.6 & 1458.1 & 1491 & 1502 & 1434.8 & 1374.2 & 1471 & 1481 \\
\hline
\end{tabular}

It is evident that semi-active controllers perform better than passive-on control for all sensor configurations except (5ID(2)). Both semi-active controllers yield substantial reduction in maximum peak/RMS values of drift and displacement, and maximum RMS acceleration, compared to passive-on control. However, maximum peak accelerations are higher except for (3A,1ID) and (10A) sensor configurations. The PI are lower for the semi-active controllers compared to passive-on control. Peak damper forces are marginally $(<3.7 \%)$ higher, but RMS damper forces are considerably $(>16 \%)$ lower, when using semi-active control vis-a-vis passive-on control.

For (5ID(1)) and (10ID) sensor configurations, OSOF-SOOVL performs better than LQG control (see square bracket percentages), and LQG performs worse than passive-on control. Similarly for (10A) and (5A) configurations, LQG-SQVL and LQG-SOOVL, respectively, perform better than OSOF control, and OSOF performs worse than passive-on control. For (10A,10ID) and (3A,3ID) configurations the performance of the most effective controller and most effective complimentary controller are comparable. For the majority of sensor configurations considered, the most effective controller involves one of the two proposed control voltage laws, i.e., SQVL or SOOVL. Hence, these are promising semi-active control laws for future studies. The significant observations from the parametric study are:

1. OSOF control with only acceleration feedback yields desired control force $\mathbf{f}_{d}$ lying in second and fourth quadrants in force-velocity plane, while applied damper force remains in first and third quadrant as per constitutive law. Hence, OSOF control does not perform well when only acceleration feedback is used since the desired force is not attainable. Therefore, to have effective OSOF control using acceleration feedback, interstorey drift feedback is also required.

2. When using only interstorey drift feedback, OSOF control performs better than passive-on and LQG control, with the later performing worst.

3. OSOF control yields better or at least comparable performance vis-a-vis passive-on/LQG control for configurations where sensor measuring interstorey drift is collocated with MR damper (Tables 3, 5).

4. Large number of sensors is not required for effective control, e.g., comparable control is achieved for configurations (5ID) and (10ID), and configurations (5A) and (10A).

5. An effective semi-active controller can be designed using as few as four sensor, as evident from results for (3A,1ID) configuration.

6. The PI contains either total system energy or top storey displacement whenever semi-active control is most effective, i.e., $Q_{2}$ or $Q_{3}$ state weighting yields best semi-active control.

\subsection{Building with two MR dampers}

\subsubsection{Comparison with available results}

In order to establish the effectiveness of the present method, maximum peak responses using OSOF are compared in Table 6 with available results from the robust reliability-based controller of Yuen et al. [13]. Here accelerations are in multiples of $g$. The comparison considers the ten storey building with MR dampers attached between storeys $0-1$ and 1-2. Four seismic excitations [13], i.e., El-Centro 50\%, 100\%, 150\%, and Kobe 50\%, are considered. Kobe JMA (1995) ground excitation data representing the N-S component measured at the Japanese Meterological Agency 
Table 7

Comparison of maximum peak/RMS response, base configuration of sensors, two damper, (Drift/Displ - cm, Accel $-\mathrm{cm} / \mathrm{s}^{2}$, Force - N)

\begin{tabular}{|c|c|c|c|c|c|c|c|c|}
\hline \multirow{3}{*}{$\begin{array}{c}\text { Response } \\
\downarrow \\
R \rightarrow\end{array}$} & \multirow{3}{*}{$\begin{array}{l}\text { Uncont } \\
\text {-rolled }\end{array}$} & \multirow{3}{*}{$\begin{array}{c}\text { Passive } \\
\text { On }\end{array}$} & \multicolumn{3}{|c|}{ OSOF } & \multicolumn{3}{|c|}{ LQG } \\
\hline & & & $\overline{C V L}$ & SQVL & SOOVL & $\mathrm{CVL}$ & SQVL & SOOVL \\
\hline & & & $10^{-05}$ & $10^{-05}$ & $10^{-05}$ & $10^{-11}$ & $10^{-05}$ & $10^{-04}$ \\
\hline Max RMS Drift & 1.3765 & 0.695 & 0.5134 & 0.4932 & 0.5183 & 0.5187 & 0.5151 & 0.5127 \\
\hline Max Peak Drift & 3.617 & 1.7819 & 1.4027 & 1.4188 & 1.3840 & 1.6087 & 1.4256 & 1.4505 \\
\hline Max RMS Displ & 8.893 & 4.0602 & 3.3097 & 3.1645 & 3.1254 & 3.2063 & 3.2241 & 3.1481 \\
\hline Max Peak Displ & 23.622 & 10.691 & 9.3840 & 8.9738 & 9.046 & 9.1881 & 9.1150 & 9.1995 \\
\hline Max RMS Accel & 388.84 & 244.27 & 209.37 & 192.79 & 210.75 & 244.70 & 224.19 & 225.38 \\
\hline Max Peak Accel & 1102 & 805.39 & 842.50 & 837.04 & 865.16 & 1096.8 & 978.22 & 1102.6 \\
\hline RMS Force $f_{1}$ & - & 561.53 & 434.12 & 450.77 & 470.09 & 435.58 & 420.56 & 439.21 \\
\hline RMS Force $f_{2}$ & - & 555.16 & 357.41 & 378.40 & 470.27 & 436.61 & 434.89 & 443.22 \\
\hline Peak Force $f_{1}$ & - & 1269.3 & 1384.7 & 1280.1 & 1269.3 & 1248.3 & 1255.1 & 1265.1 \\
\hline Peak Force $f_{2}$ & - & 1189.3 & 1076.3 & 1111.4 & 1227.2 & 1212.6 & 1217.0 & 1226.5 \\
\hline PI Semi-active & - & - & 301.33 & 287.21 & 300.36 & 267.82 & 302.85 & 647.48 \\
\hline PI Passive On & - & - & 464.41 & 464.41 & 464.41 & 402.06 & 464.41 & 1025.6 \\
\hline
\end{tabular}

Station, Kobe, is considered [23]. Controller-A considers SQVL, $\mathbf{Q}=\operatorname{diag}\left[\begin{array}{ll}\mathbf{K}_{s} & \mathbf{M}_{s}\end{array}\right]$ (i.e., total energy of system is weighted), $\mathbf{R}=10^{-5} \mathbf{I}_{2 \times 2}$, with accelerations measured at each storey and interstorey drift measured between storeys 0-1 and 1-2. Controller-B considers SOOVL, $\mathbf{Q}=\mathbf{C}^{\mathbf{T}} \operatorname{diag}[\mathbf{0}$ 1] $\mathbf{C}$ (i.e., top storey acceleration is weighted), $\mathbf{R}=10^{-6} \mathbf{I}_{2 \times 2}$, with interstorey drift measured between storeys 0-1, 1-2, 4-5, 6-7, and 8-9. Controller-1 and Controller-2 from [13] pertain to accelerations measured at the current time step, and at the current and previous time step, respectively, being fedback from storeys $1,2,3,8,10$.

The comparison broadly shows that Controller-A with El Centro excitation performs better in acceleration response; Controller-A with Kobe excitation performs better in displacement response; Controller-B with El Centro excitation performs better for displacement but worse for drift and acceleration response; Controller-B with either El Centro or Kobe excitation yields lower damper force; and all other responses are comparable across all four controllers.

\subsubsection{Base sensor configuration - Peak and RMS response}

Control weighting $\mathbf{R}=R \mathbf{I}_{2 \times 2}$ is considered where $R$ is a constant that weights the MR dampers equally. The base configuration of sensors considered is (10A, 2ID), with interstorey drifts measured at ground and first storey where dampers are attached. The value of $R$, corresponding to most effective control, is indicated in Table 7 . State weighting $\mathbf{Q}=\operatorname{diag}\left[\begin{array}{ll}\mathbf{K}_{s} & \mathbf{M}_{s}\end{array}\right]$ is considered. Comparing Table 7 with Table 2, a further reduction in controlled response is evident, due to the usage of a second damper. However, when comparing various controllers the overall trend remains unchanged vis-a-vis the single damper case.

Table 7 shows that OSOF control achieves substantial reduction $(>12 \%)$ in maximum peak/RMS responses, except for an increase $(<7.5 \%)$ in maximum peak acceleration, vis-a-vis passive-on control. OSOF yields comparable or lower drift/displacement and significant reduction (up to 23\%) in acceleration vis-a-vis LQG control. The maximum peak damper force from OSOF shows an increase (up to $11 \%$ ) vis-a-vis other controllers, while maximum RMS damper force shows a considerable reduction $(>16 \%)$ vis-a-vis passive-on control but an increase $(<8.5 \%)$ vis-a-vis LQG control. Except for LQG-CVL, OSOF yields lowest PIs. For OSOF control, the performance of proposed SOOVL, SQVL is comparable to the existing CVL, with SQVL providing lowest RMS responses.

LQG affords a reduction $(>9 \%)$ in maximum peak/RMS drift/displacement, substantial $(>21 \%)$ increase in peak acceleration, marginal $(<2 \%)$ reduction in maximum peak damper force, substantial $(>21 \%)$ reduction in maximum RMS damper force, and lower PI, vis-a-vis passive-on control. The performance of proposed SOOVL and SQVL, for LQG control, ranges from comparable to significantly-better vis-a-vis existing CVL. Thus, as in the single damper case, OSOF control is quite effective vis-a-vis passive-on/LQG control when deploying two dampers. Performance of the proposed voltage laws (SQVL, SOOVL) ranges from comparable to significantly-better vis-a-vis CVL. Storeywise comparisons are omitted as the trend is similar to the one damper case.

\subsubsection{Parametric studies - Peak and RMS response}

Table 8 shows sensor configurations considered. Results for all sensor configurations are compared in Table 9 in a manner analogous to Table 5. The sensor configurations and corresponding most effective complimentary contro- 
Table 8

Sensor configurations with two dampers

\begin{tabular}{|c|c|c|c|c|c|c|c|c|}
\hline \multirow{3}{*}{$\begin{array}{c}\text { Storey } \\
\text { No. }\end{array}$} & \multicolumn{8}{|c|}{ Sensor Configuration } \\
\hline & \multicolumn{4}{|c|}{ (० Accelerometer } & \multicolumn{2}{|c|}{$\times \quad$ LVDT Sensor) } & \multirow[b]{2}{*}{ 10A,1ID } & \multirow[b]{2}{*}{$5 \mathrm{~A}$} \\
\hline & $10 \mathrm{~A}, 2 \mathrm{ID}$ & 5ID & $10 \mathrm{~A}, 10 \mathrm{ID}$ & $2 \mathrm{~A}, 3 \mathrm{ID}$ & $5 \mathrm{~A}, 5 \mathrm{ID}$ & $5 \mathrm{~A}, 2 \mathrm{ID}$ & & \\
\hline 10 & 0 & & $\circ \times$ & 0 & 0 & 0 & 0 & \\
\hline 9 & o & $x$ & $\circ \times$ & & ० & & o & ○ \\
\hline 8 & ० & & $\circ \times$ & ० & ० & ○ & o & \\
\hline 7 & o & $x$ & $\circ \times$ & & ० & & o & $\circ$ \\
\hline 6 & 0 & & $\circ \times$ & & 0 & & 0 & \\
\hline 5 & ० & $x$ & $\circ \times$ & $\times$ & $\times$ & & ० & $\circ$ \\
\hline 4 & 0 & & $0 \times$ & & $x$ & & 0 & \\
\hline 3 & 0 & & $0 \times$ & & $x$ & 0 & 0 & \\
\hline 2 & $\circ \times$ & $x$ & $\circ \times$ & $x$ & $x$ & $\circ \times$ & ० & $\circ$ \\
\hline 1 & $\circ \times$ & $\times$ & $\circ \times$ & $\times$ & $\times$ & $0 \times$ & $0 \times$ & o \\
\hline
\end{tabular}

Table 9

Maximum peak/RMS response for various sensor configurations, two dampers, (Drift/Displ - cm, Accel $-\mathrm{cm} / \mathrm{s}^{2}$, force - N)

\begin{tabular}{lccccccc}
\hline SensorConfig $\rightarrow$ & SID & 10A,10ID & 2A,3ID & 5A,5ID & 5A,2ID & 10A,1ID & 5A \\
\hline Response & OSOF & OSOF & LQG & LQG & LQG & LQG & LQG \\
$\downarrow$ & SOOVL & SQVL & SQVL & SQVL & SQVL & SQVL & SQVL \\
\multicolumn{1}{c}{$R \rightarrow$} & $Q_{1}$ & $Q_{2}$ & $Q_{3}$ & $Q_{3}$ & $Q_{3}$ & $Q_{3}$ & $Q_{2}$ \\
\hline Max RMS Drift & 0.5116 & 0.5010 & 0.5320 & 0.5125 & 0.5049 & 0.5022 & 0.5153 \\
& {$[-25.0]$} & {$[-0.24]$} & {$[0.08]$} & {$[-12.9]$} & {$[-24.3]$} & {$[-24.8]$} & {$[-37.9]$} \\
Max Peak Drift & 1.4211 & 1.3668 & 1.4715 & 1.4197 & 1.4572 & 1.4525 & 1.5589 \\
& {$[-22.5]$} & {$[-5.90]$} & {$[-3.61]$} & {$[-15.0]$} & {$[-16.0]$} & {$[-24.7]$} & {$[-37.5]$} \\
Max RMS Displ & 3.1250 & 3.0955 & 3.2695 & 3.2887 & 3.1076 & 3.0985 & 3.2398 \\
& {$[-29.5]$} & {$[-0.11]$} & {$[4.75]$} & {$[1.40]$} & {$[-17.2]$} & {$[-26.1]$} & {$[-43.4]$} \\
Max Peak Displ & 8.3056 & 8.9930 & 9.3397 & 9.3310 & 8.9500 & 8.9239 & 9.1172 \\
& {$[-28.0]$} & {$[0.77]$} & {$[12.6]$} & {$[6.27]$} & {$[-14.2]$} & {$[-18.6]$} & {$[-45.2]$} \\
Max RMS Accel & 217.86 & 203.17 & 209.27 & 209.83 & 214.68 & 215.03 & 223.05 \\
& {$[-8.55]$} & {$[-5.52]$} & {$[-10.8]$} & {$[-4.83]$} & {$[-6.90]$} & {$[-5.73]$} & {$[-11.7]$} \\
Max Peak Accel & 952.07 & 871.98 & 770.27 & 868.02 & 843.94 & 843.28 & 977.26 \\
& {$[18.4]$} & {$[3.40]$} & {$[-9.32]$} & {$[0.69]$} & {$[-7.03]$} & {$[1.73]$} & {$[21.1]$} \\
RMS Force $f_{1}$ & 411.22 & 442.03 & 465.88 & 400.91 & 430.37 & 428.28 & 414.16 \\
RMS Force $f_{2}$ & 462.75 & 441.59 & 480.04 & 437.86 & 455.51 & 451.72 & 430.78 \\
Peak Force $f_{1}$ & 1241.0 & 1249.7 & 1258.4 & 1244.2 & 1287.4 & 1288.3 & 1255.2 \\
Peak Force $f_{2}$ & 1226.8 & 1218.3 & 1211.0 & 1228.5 & 1244.0 & 1245.4 & 1216.4 \\
PI Semi-active & 51.30 & 251.49 & 0.0107 & 0.0143 & 0.01358 & 0.0135 & 303.75 \\
PI Passive On & 65.90 & 408.30 & 0.0165 & 0.0227 & 0.0227 & 0.0227 & 464.41 \\
\hline
\end{tabular}

ller are: $(5 \mathrm{ID}) \rightarrow\left(\right.$ LQG-CVL, $\left.Q_{1}, R=10^{-11}\right)$; (10A, 10ID $) \rightarrow\left(\right.$ LQG-SQVL, $\left.Q_{3}, R=10^{-09}\right)$; (2A, 3ID) $\rightarrow$ (OSOF-SOOVL, $\left.Q_{1}, R=10^{-06}\right)$; (5A, 5ID) $\rightarrow$ (OSOF-SOOVL, $\left.Q_{3}, R=10^{-11}\right)$; (5A,2ID) $\rightarrow$ (OSOF-SOOVL, $\left.Q_{1}, R=10^{-11}\right) ;(10 \mathrm{~A}, 1 \mathrm{ID}) \rightarrow\left(\right.$ OSOF-SOOVL, $\left.Q_{4}, R=10^{-09}\right) ;(5 \mathrm{~A}) \rightarrow\left(\right.$ OSOF-CVL, $\left.Q_{1}, R=10^{-07}\right)$.

As in the one-damper case, both semi-active controllers yield substantial reduction in response (except for maximum peak acceleration), reduction in PI, and substantial reduction ( $>14.5 \%)$ in RMS damper forces. Maximum peak damper forces are comparable across all controllers. For (5ID) sensor configuration, OSOF-SOOVL performs substantially better than the corresponding most effective complimentary controller (i.e., LQG-CVL), and LQGCVL is comparable to passive-on control (compare percentages in parentheses and square brackets). For (5A) configuration, LQG-SQVL performs substantially better than the corresponding most effective complimentary controller (i.e., OSOF-CVL), and OSOF-CVL performs significantly worse than passive-on control. For (10A,10ID) configuration the performance of the most effective controller (OSOF-SQVL) and most effective complimentary controller (LQG-SQVL) are comparable. For all sensor configurations considered, the most effective controller involves either SQVL or SOOVL. The observations noted in Section 5.1.3 from parametric studies with a single damper are reconfirmed for the two-damper case. 


\section{Conclusions}

Optimal Static Output Feedback (OSOF) control is used to determine the desired force (control input) required from a set of interstorey MR dampers in a ten storey building. The modified Bouc-Wen damper model is considered. This exhibits a non-linear relationship between damper force and input-voltage/states, making it difficult to obtain the input voltage required to realize a desired control force. Hence, three voltage laws (i.e., SQVL and SOOVL which are proposed, and the existing CVL) are used to obtain the applied voltage for a given desired force and state. The performance of OSOF, LQG, and passive-on controllers are compared. The significant conclusions are:

- The time for online computations using OSOF control is two orders of magnitude less than that for LQG control.

- When compared to the robust reliability-based controller in [13], OSOF control shows comparable results for El Centro excitation and somewhat better results for Kobe excitation.

- For single damper and base configuration of sensors, OSOF control mostly yields considerable reduction in maximum peak/RMS responses compared to passive-on/LQG control. The PI is lowest when using OSOF control, thus proving its efficacy. OSOF-SOOVL and LQG-SOOVL controllers are quite effective in reducing storywise peak/RMS values of drift/displacement compared to passive-on control, with OSOF-SOOVL being most effective.

- For two dampers and base configuration of sensors, OSOF control yields considerable reduction in maximum peak/RMS responses, except maximum peak acceleration, compared to passive-on control. OSOF yields comparable or lower values for maximum peak/RMS drift/displacement and significant reduction in maximum peak/RMS acceleration vis-a-vis LQG control. With the exception of LQG-CVL, the lowest PI result from OSOF control.

- Parametric studies reveal that an effective controller can be designed with a few sensor output measurements (interstorey drift and/or acceleration) using appropriate state weighting $\mathbf{Q}$ and control weighting $\mathbf{R}$. When using OSOF, the output measured must include at least one interstorey drift, else the required and desired damper force will be out of phase rendering the control ineffective. Further, the control is more effective when interstorey drift sensor is collocated with the MR damper.

- The proposed control voltage laws (SOOVL, SQVL) are comparable or better than the existing CVL.

It may be noted that the solution of Eqs $(12,13,14)$ would in general yield multiple local minima of the performance index $J$. Convergence to a particular minima is greatly influenced by the choice of initial stabilizing gain $\left(\mathbf{K}_{0}\right)$. The present algorithm used to solve the OSOF problem does not yield the global minimum $J$ (although the resulting control is quite effective). Future studies would focus on determining optimal placement of dampers and optimal state/control weighting that minimize multiple objectives (such as the PI, $J$, and a set of peak/RMS responses at chosen storey levels). Better analytical as well as ANN based voltage laws, representing a more accurate inversion of damper dynamics, could also be explored.

\section{References}

[1] Y.K. Wen, Method for random vibration of hysteretic systems, ASCE Journal of Engineering Mechanics Divison 102(2) (1976), $249-263$.

[2] C.W. Wong, Y.Q. Ni and J.M. Ko, Steady state oscillation of hysteretic differential model II: performance analysis, ASCE Journal of Engineering Mechanics 120(11) (1994), 2299-2325.

[3] B.F. Spencer, S.J. Dyke, M.K. Sain and J.D. Carlson, Phenomenological model for magnetorhelogical dampers, ASCE Journal of Engineering Mechanics 123(3) (1997), 230-238.

[4] A. Dominguez, R. Sedaghati and I. Stiharu, A new dynamic hysteresis model for magnetorhelogical dampers, Smart Materials and Structures 15 (2006), 1179-1189.

[5] L.X. Wang and H. Kamath, Modelling hysteretic behaviour in magnetorhelogical fluids and dampers using phase-transition theory, Smart Materials and Structures 15 (2006), 1725-1733.

[6] R. Jiménez and L. Álvarez-Icaza, LuGre friction model for a magnetorhelogical damper, Structural Control and Health Monitoring 12 (2005), 91-116.

[7] C. Sakai, H. Ohmori and A. Sano, Modeling of MR damper with hysteresis for adaptive vibration control, Proceedings of the 42 ${ }^{\text {nd }}$ IEEE conference on decision and control, USA, 2003, 3840-3845.

[8] Z.D. Xu and Y.P. Shen, Intelligent bi-state control for the structure with magnetorhelogical dampers, Journal of Intelligent Material Systems and Structures 14 (2003), 35-42. 
[9] S.J. Dyke, B.F Spencer, M.K. Sain and J.D. Carlson, Modelling and control of magnetorhelogical dampers for seismic response reduction, Smart Materials and structures 5(5) (1996), 565-575.

[10] L.M. Jansen and S.J. Dyke, Semi-active control strategies for MR dampers: A comparative study, ASCE Journal of Engineering Mechanics 126(8) (2000), 795-803.

[11] C.C. Chang and L. Zhou, Neural network emulation of inverse dynamics for a magnetorhelogical damper, ASCE Journal of Structural Engineering 128(2) (2002), 231-239.

[12] G.B. Motra, W. Mallik and N.K. Chandiramani, Semi-active vibration control of connected buildings using magnetorheological dampers, Journal of Intelligent Material Systems and Structures 22(16) (2011), 1811-1827.

[13] K.V. Yuen, Y. Shi, J.L. Beck and H.F. Lam, Structural protection using MR dampers with clipped robust reliability-based control, Journal of Structural and Multidisciplinary Optimization 34 (2007), 431-443.

[14] R.S. Prabhakar, C. Sujahta and S. Narayanan, Optimal semi-active preview control response of a half car vehicle model with magnetorhelogical damper, Journal of Sound and Vibration 326 (2009), 400-420.

[15] L.L. Chung, C.C. Lin and S.Y. Chu, Optimal direct output feedback of structural control, ASCE Journal of Engineering Mechanics 119(11) (1993), 2157-2173.

[16] E.E. Matheu, M.P. Singh and C. Beattie, Output-feedback sliding-mode control with generalized sliding surface for civil structures under earthquake excitation, Earthquake Engineering and Structural Dynamics 27(3) (1998), 259-282.

[17] S.P. Purohit and N.K. Chandiramani, Optimal static output feedback control of a building using an MR damper, Structural Control and Health Monitoring 18 (2011), 852-868.

[18] F.L. Lewis and V.L. Syrmos, Optimal Control, John Wiley, USA, 1995.

[19] S.Y. Chu, T.T. Soong and A.M. Reinhorn, Active, Hybrid and Semi-active Structural Control - A Design and Implementation Handbook, John Wiley, USA, 2005.

[20] W.S. Levine and M. Athens, The determination of the optimal constant output feedback gains for linear multivariable systems, IEEE Transactions on Automatic Control AC-15 (1970),44-48.

[21] D.D. Moerder and A.J. Calise, Convergence of a numerical algorithm for calculating optimal output feedback gains, IEEE Transactions on Automatic Control AC-30 (1985), 900-903.

[22] Vibration Data El Centro Earthquake. Available from: http://www.vibrationdata.com/elcentr -o.htm (accessed 24 December 2008).

[23] Y. Ohtori, R.E. Christenson, B.F. Spencer and S.J. Dyke, Benchmark control problems for seismically excited nonlinear buildings, ASCE Journal of Engineering Mechanics 130(4) (2004), 366-385. 

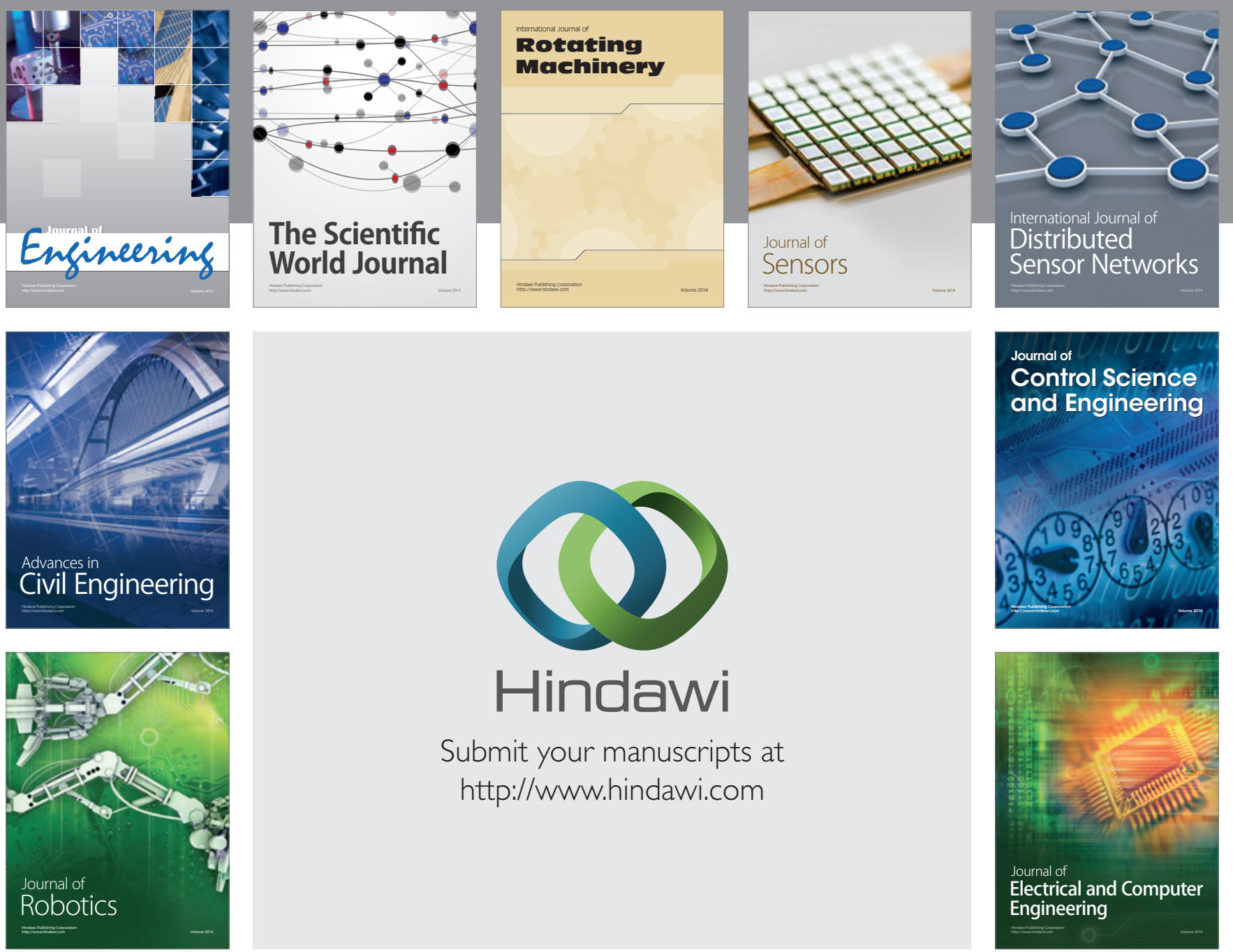

Submit your manuscripts at

http://www.hindawi.com
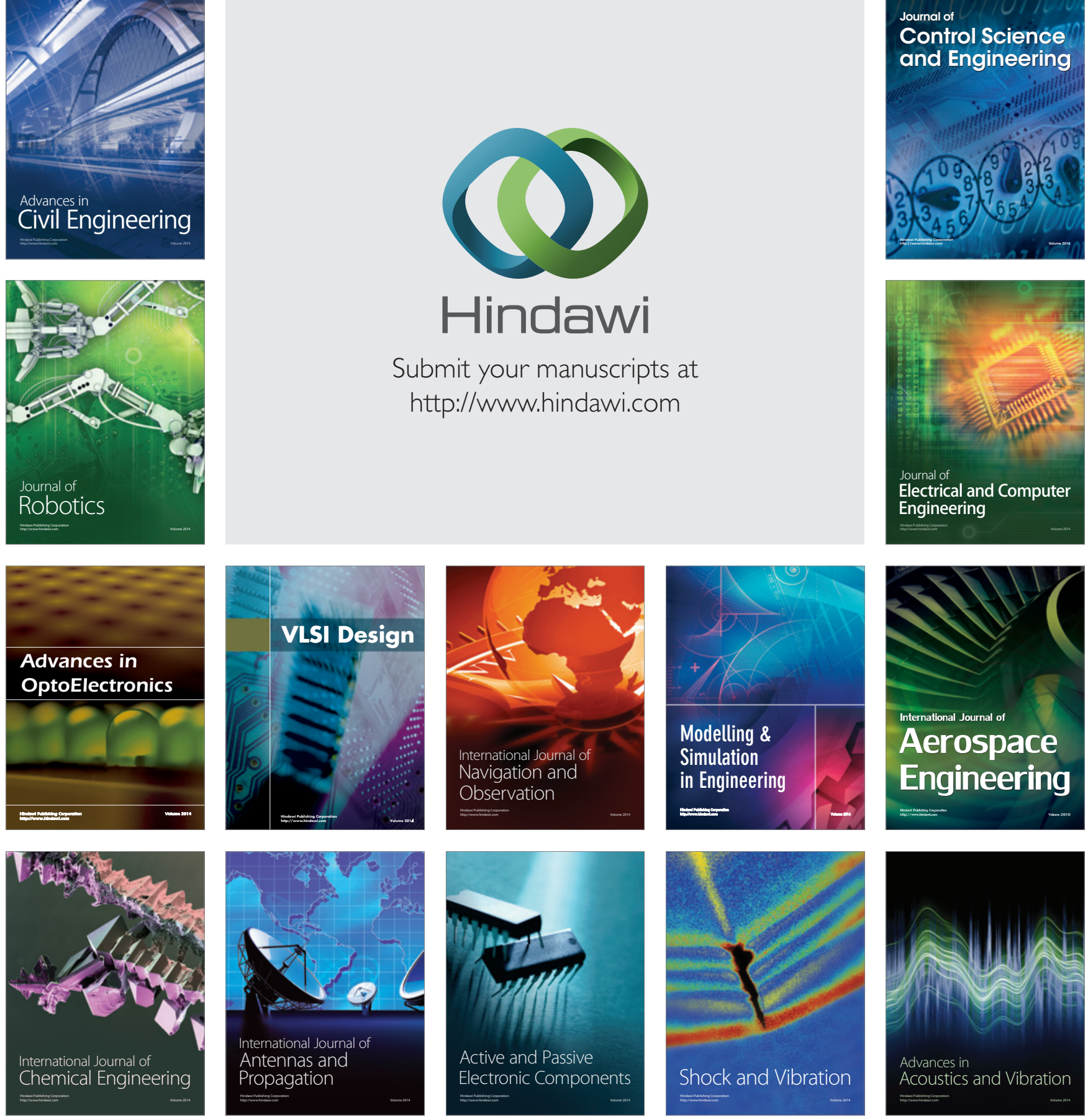